\title{
Unilateral Agenesis of Lung, Kidney with Cardiac and Vertebral Defects a Rare Association
}

\author{
Maji $B^{1}$, Ganguly $N^{2}$, Ghosh $A^{3}$
}

\begin{abstract}
Unilateral lung agenesis initially misdiagnosed as unilateral massive pleural effusion with collapse of lung, and after several investigations, including ultrasonography or CT scan of thorax, fibre-optic bronchoscopy or bronchography, a final diagnosis of unilateral absence of lung is made. An anomaly scan may also reveal associated renal, cardiac and vertebral defects. Here we report a 7 months old female who presented with respiratory distress since birth and after a thorough investigation, she was found to have this rare association of pulmonary-renal-cardiacvertebral defect.
\end{abstract}

Key words: Pulmonary agenesis, Renal agenesis, Cardiac anomaly, Vertebral defect.

\section{Introduction}

$\mathrm{P}$ ulmonary agenesis is an extremely rare condition with a reported prevalence of 34 per million live births ${ }^{1}$. Left sided pulmonary agenesis is more common and they have a longer life expectancy than those with right sided pulmonary agenesis ${ }^{2}$, which is more commonly associated with other congenital abnormalities like cardio-vascular, skeletal, gastrointestinal or genitor-urinary system. Muhamed $^{3}$ reported The first case from India in 1923, after a medico legal autopsy which showed left sided pulmonary agenesis. But the frequency of the full spectrum of this pulmonary-cardio-renalvertebral association is not known.

\section{The Case}

A Five months old boy $(6.1 \mathrm{~kg}$ ) was referred to our hospital as emergency basis with the complaints of progressively increasing cough, fever, noisy breathing and difficulty in respiration for last ten days. He was provisionally diagnosed as a case of left sided massive pleural effusion. There was no history of choking during feeding, foreign body inhalation, vomiting, suck-rest-suck cycle and/or cyanosis. The patient was suffering from similar type of illness since birth but never needed hospital admission because the attacks were never so serious. He was born of a non-consanguineous marriage in a Hindu family from a 32 years old third gravida mother who had previous two normal girl children. Antenatal period was uneventful without any exposure to radiation or teratogen. He has born at term
'Dr. Biplab Maji, MBBS, MD, Resident, ${ }^{2}$ Dr. Nupur Ganguly, MBBS, DCH, DNB, Associate Professor, ${ }^{3}$ Dr. Apurba Ghosh, MBBS, DCH, MRCPCH, Professor and Director. All from the Institute of Child Health, Park Circus, Kolkata, India.

\section{Address for correspondence \\ Dr. Biplab Maji \\ E-mail:dr.biplab.maji@gmail.com}

\section{How to cite}

Maji B, Ganguly N, Ghosh A. Unilateral Agenesis of Lung, Kidney with Cardiac and Vertebral Defects a Rare Association. J Nepal Paediatr Soc 2014:34(1):77-79.

doi: http://dx.doi.org/10.3126/jnps.v34i1.8898

This work is licensed under a Creative Commons Attribution 3.0 License.

(c) (i)

gestation, by normal vaginal delivery in hospital, without any complications. There was no family history of any congenital malformation or unexpected death. Developmental milestones were normal for age. The CXR - PA view done outside showed right upper lobe consolidation with diffuse opacity of left chest and mediastinal shift towards left.

On examination, he was active, alert with normal anthropometry but had severe respiratory distress. General physical examination was unremarkable except a mild hypotonia of all four limbs. He had tachycardia (heart rate-180/min), tachypnea (respiratory rate-94/min), grunting with intercostal and subcostal retractions but no cyanosis. The oxygen saturation was $90 \%$ 


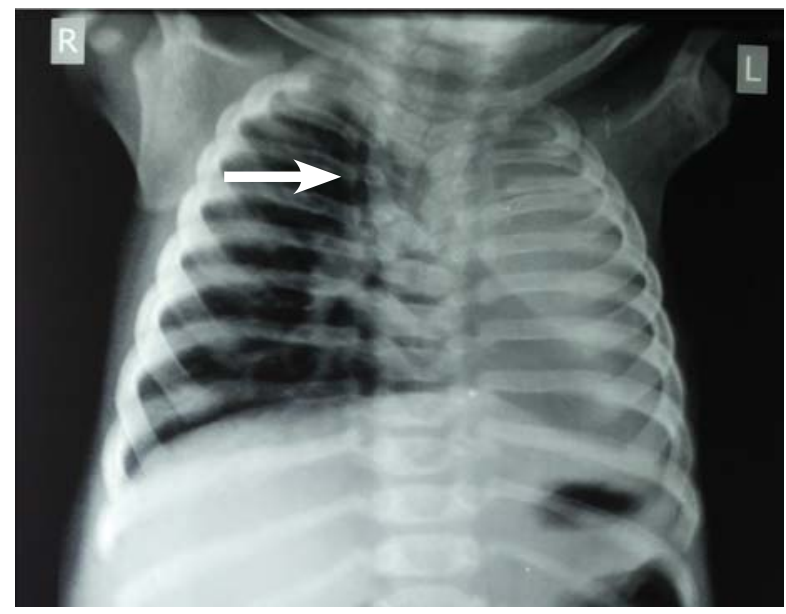

Fig 1: CXR PA view showing absence of left lung with mediastinal shift towards left and vertebral anomaly at the level of $D 4,5,6$.

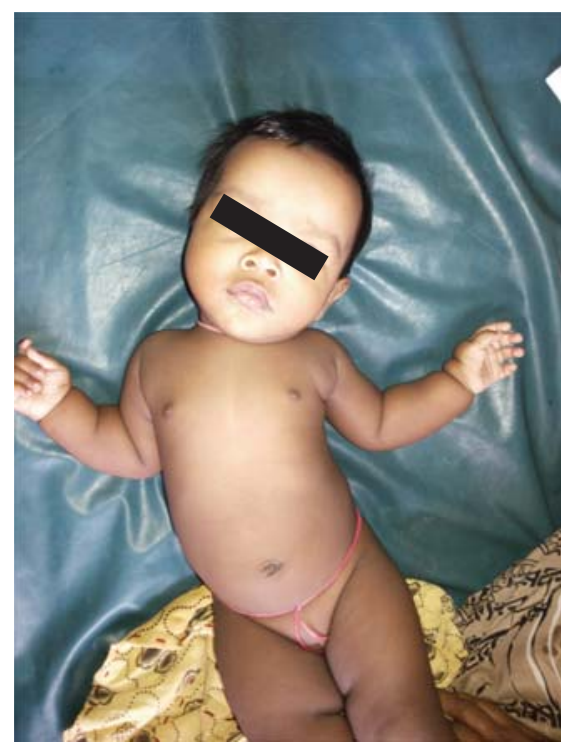

Fig 2: Showing scoliosis towards left

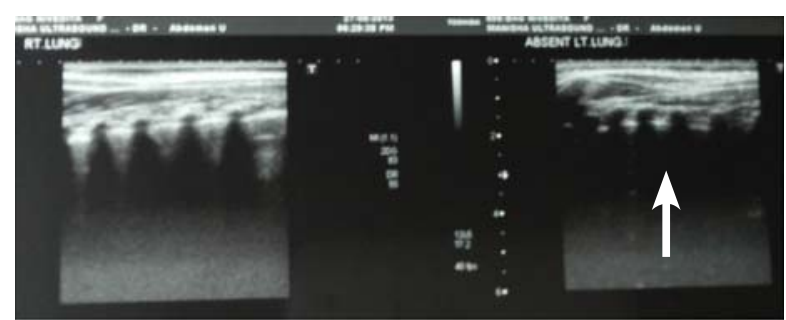

Fig3: Ultrasonography of chest showed absence of left lung.

with oxygen. His chest was abnormal shaped, with decreased movements on leftside (Fig 2). Trachea was deviated towards leftside. Apex beat was palpable on left side at $4^{\text {th }}$ intercostal space in anterior axillary line. There was dull percussion note on the whole of the left side of chest. Breath sounds were absent on the left side. Cardiac examination revealed a soft diastolic

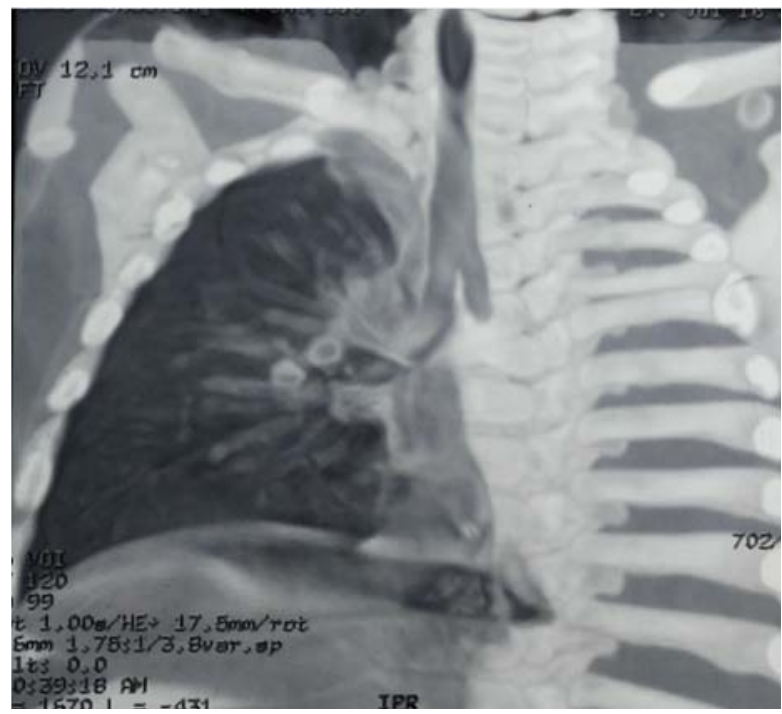

Fig 4: CT Chest revealed absence of left main bronchus just after the bifurcation with no lung tissue in the left chest.

murmur with wide and fixed splitting of second heart sound. On abdominal examination, liver was palpated on right side, one $\mathrm{cm}$ below costal margin. Chest $X$ ray (Fig. 1) showed complete opacification of the left hemithorax without air bronchogram, and with mediastinal shift towards left. Lung on right side was enlarged with gross herniation to the left .Cardiac silhouette was not visible in the right side because of intrathoracic displacement of heart. CT Chest (Fig. 4) showed complete opacification of left hemithorax with visualization of the proximal part of the ipsilateral main bronchus as well aspulmonary artery and vein. There was trans-mediastinal herniation of hyperinflated left lung towards left side. Heart, trachea, oesophagus, and great vessel of mediastinum were grossly deviated to left side. Diagnosis of complete agenesis of left lung was made. In echocardiography, he was found to have small ( $6 \mathrm{~mm}$ ) Ostium secondum atrial septal defect with significant left to right shunting, absent left pulmonary artery, mild pulmonary artery hypertension but normal sized cardiac chambers. Cranial as well as abdominal ultrasounds were unremarkable, except absence of the left kidney. Bone scan revealed cleft vertebra with spina bifida at upper dorsal level. There was no other gross congenital anomaly found on anomaly scans. Patient improved on intra venous antibiotics and conservative treatment in seven days and discharged home in clinically stable condition with an advice of three monthly follow-up.

\section{Discussion}

Morgagni in 1762 first described congenital underdevelopment of the lungs ${ }^{4}$. This entity is believed 
to be caused by failure of the developmental balance between the two lung buds at approximately 4th week of gestation due to unknown aetiology ${ }^{5}$.Though Genetic, teratogenic and mechanical factors may be responsible for these ${ }^{6}$, but they are generally sporadic, with only a few reports of these conditions occurring in siblings in an autosomal recessive pattern.

Monaldi divided the mal-development of lung in four groups. Group I: No bifurcation of trachea; Group II: Only rudimentary main bronchus; Group III: Incomplete development after division of main bronchus; and Group IV: Incomplete development of sub segmental bronchi and small segment of the corresponding lobe. The present case belongs to the second group of Monaldi classification.

According to Boyden ${ }^{7}$ there are three degrees of maldevelopment: (i) agenesis, in which there is complete absence of lung tissue, (ii) aplasia, in which rudimentary bronchus is present but no lung tissue is present, and (iii) hypoplasia, in which all the normal pulmonary tissues are present but are under-developed.

The incidence of unilateral pulmonary agenesis is one in every 10,000 to 15,000 autopsies. Almost $50 \%$ of the patients have associated anomalies of the other systems. Left pulmonary agenesis is often an isolated finding but recently, De George syndrome $^{8}$ and velocardiofacial syndrome have been reported in association with left pulmonary agenesis. In contrast, right pulmonary agenesis is frequently $(>50.0 \%)$ associated with congenital malformations in cardiovascular (14\%), gastrointestinal (14\%), skeletal (12\%), and genitourinary (9\%) system ${ }^{9}$. Recurrent pulmonary infections, decreased exercise tolerance, and mild dyspnea during exertion are the most common symptoms. Less frequently found are hemoptysis and signs of pulmonary hypertension. Diagnosis may be established with help of chest x-ray, CT thorax ${ }^{10}$, fibre-optic bronchoscopy, and if possible pulmonary angiography and bronchography .A hypoplastic lung may show some benefits with intrauterine repeated amniofusions, surfactant administration ,intrauterine vesicoamniotic shunts and endoscopic ablation of valves and PLUG (plug the lung until it grows) by fetoscopic tracheal occlusion with a clip. After delivery respiratory support is given ranging from oxygen to mechanical ventilation including ECMO (Extracorporeal membrane oxygenation). Dialysis may be required for support of renal function. Prophylaxis for respiratory syncytial virus, pneumococcus, influenza infections are recommended.

\section{Conclusion}

Unilateral agenesis of lung is an uncommon condition, frequently associated with other congenital anomalies. Sometimes it is misdiagnosed as massive pleularal effusion with collapse of the lung. An ultrasonography of the chest can easily differentiate between these two conditions.

\section{References}

1. Borja AR, Ransdell HT Jr, Villa S. Congenital development arrest of the Lung. Am Thorac Surg 1970;10(4):317-26.

2. Spencer H. editor: Pathology of the lung, ed 4, vol 1, pp 413-510. Oxford, 1985. Pergamon.

3. Muhamed KSN. Absence of left lung. Ind Med Gaz 1923;58:262-4.

4. Benson J E, Olen M M, Fletcher B D. A spectrum of bronchopulmonary anomalies associated with tracheoesophagealmalformation. Pediatr Radiol 1985;(6)15:377-80.

5. Berrocal T, Madrid C, Novo S, Gutierrez J, Arjonilla A, Gomez-Leon N. Congenital anomalies of the tracheobronchial tree, lung, and mediastinum: embryology, radiology, and pathology. Radiographics 2004;24:e17.

6. Maltz DL, Nadas AS. Agenesis of the lung: presentation of eight new cases and review of literature. Pediatrics 1968;42:175-88.

7. Boyden EA. Developmental anomalies of the lungs. Am J Surg 1955;89:79-89.

8. FitozS, Ucar T, Erden A, Gunlemez A. Degeorge syndrome associated with left lung aplasia. $\mathrm{Br} J$ Radiol 1992;65:221- Z24.

9. Maltz DL, Nadas AS. Agenesis of the lung: presentation of eight new cases and review of literature. Pediatrics 1968;42:175-88.

10. Mata JM, Caceres j, Lucaya J. et al.: CT of congenital malformations of lung. Radiographics 1990;10:651 